\section{FRI0218 VALIDATION OF ASSESSMENTS IN SPONDYLOARTHRITIS INTERNATIONAL SOCIETY (ASAS) MRI LESION DEFINITIONS IN AXIAL SPONDYLOARTHRITIS: DATA FROM THE ECHOGRAPHY IN SPONDYLOARTHRITIS COHORT (ECHOSPA)}

W.P. Maksymowych ${ }^{1}$, D. Loeuille², S. Wichuk ${ }^{3}$, J. Paschke ${ }^{4}$, O. Judet ${ }^{5}$, M. Breban ${ }^{6}$, M.-A. D'Agostino $0^{6}$, R.G. Lambert ${ }^{7}{ }^{1}$ Rheumatology, University of Alberta, Edmonton, Canada; ${ }^{2}$ Rheumatology, CHRU Vandoeuvre les Nancy, Nancy, France: ${ }^{3}$ Medicine, University of Alberta: ${ }^{4}$ CaRE Arthritis, Edmonton, Canada; ${ }^{5}$ Radiology; ${ }^{6}$ Rheumatology, Ambroise Paré Hospital, BoulogneBillancourt, France; ${ }^{7}$ Radiology, University of Alberta, Edmonton, Canada

Background: The diversity of MRI lesions in the sacroiliac joints of patients with axial spondyloarthritis (axSpA) has only recently been appreciated and consistent terminology, descriptions, and definitions have not yet been internationally accepted. The ASAS MRI group has generated updated consensus lesion definitions and these now require validation to support widespread adoption for clinical practice and research.

Objectives: To assess the distribution by diagnosis, reliability of detection, and construct validity of active and structural lesions as defined by the ASAS-MRI group on MRI scans from the ECHOSPA cohort.

Methods: Consecutive outpatients with age $<50$ years and symptoms $>3$ months suggestive of SpA (inflammatory back pain, peripheral arthritis or inflammatory arthralgia, enthesitis or dactylitis, uveitis with B27 positivity, a family history of $\mathrm{SpA}$ ) were enrolled in the prospective French ECHOSPA cohort. MRI scans from 412 of the 470 recruited cases were available for evaluation by 2 readers and an adjudicator. ASAS_MRI_def ${ }^{n}$ were recorded in an ASAS consensus-derived eCRF that comprises global assessment (active and/or structural lesion typical of axSpA present/absent) and detailed scoring of individual lesions (SPARCC SIJ inflammation, SPARCC SIJ structural). Definite lesions were defined according to confidence $\geq 3$ ( $0-4$ scale). Reliability of detection of lesions assessed as present/ absent by global assessment was analysed using kappa and detailed scoring of SIJ quadrants by intra-class correlation coefficient (ICC). For construct validity we calculated optimal cut-offs for bone marrow oedema (BME) and erosion that defined active and structural lesion typical of axSpA, respectively.

Results: At baseline, mean age of the 412 cases with MRI scans was 39.3 years, mean duration of symptoms was 2.5 years, $41.3 \%$ were HLA-B27 positive, and $63.2 \%$ were female. Active and structural lesions typical of axSpA were present in $9.7 \%$ and $10.8 \%$, respectively, and ASAS positive MRI in $9.3 \%$. Subchondral BME (13.6\%) and erosion (9.4\%) were the most frequent active and structural lesions, respectively. Active but not structural lesions were present in $3.0 \%$ while the converse was evident in $4.0 \%$. AxSpA was diagnosed at baseline in $88.1 \%$ and all categories of active and structural lesions were higher in those with axSpA. Substantial $\kappa$ values $(95 \% \mathrm{Cl})$ were evident for detection of these lesions with comparable reliability for active and structural lesions: active lesion $(0.76(0.65-$ $0.88)$ ), ASAS positive MRI (0.78 (0.66-0.89), structural lesion (0.76 (0.65-0.87). Detailed scoring per SIJ quadrant that reflect expert opinion as to what constitutes an active or structural lesion typical of axSpA are provided in the table 1.

Abstract FRI0218 - Table 1

\begin{tabular}{|c|c|c|}
\hline \multirow{2}{*}{$\begin{array}{c}\text { Number of SIJ } \\
\text { Quadrants }\end{array}$} & \multicolumn{2}{|c|}{ Active Lesion Typical of AxSpA } \\
\cline { 2 - 3 } & Sensitivity & Specificity \\
\hline BME Score $\geq 2$ & $100 \%$ & $90.27 \%$ \\
\hline BME Score $\geq 3$ & $100 \%$ & $95.14 \%$ \\
\hline BME Score $\geq 4$ & $97.5 \%$ & $96.76 \%$ \\
\hline & Structural Lesion Typical of AxSpA \\
\cline { 2 - 3 } & Sensitivity & Specificity \\
\hline Erosion Score $\geq 2$ & 84.09 & 99.15 \\
\hline Fat metaplasia $\geq 2$ & 27.27 & 98.02 \\
\hline Backfill $\geq 2$ & 11.36 & 100 \\
\hline Ankylosis $\geq 2$ & 4.55 & 99.72 \\
\hline
\end{tabular}

Conclusions: SPARCC BME score of $\geq 3$ and Erosion Score $\geq 2$ may optimally reflect active and structural lesions typical of axSpA, respectively. MRI lesions defined by the ASAS-MRI group can be reliably detected.

Disclosure of Interest: None declared

DOI: 10.1136/annrheumdis-2018-eular.7278

\section{FRI0219 \\ ANALYSIS OF THE DIFFERENT VALUE OF MAGNETIC RESONANCE IMAGING CHANGES IN THE SACROILIAC JOINTS FOR A DIAGNOSIS OF AXIAL SPONDYLOARTHRITIS AS JUDGED BY RHEUMATOLOGISTS AND RADIOLOGISTS}

X. Baraliakos, A. Ghadir, M. Fruth, U. Kiltz, J. Braun. Rheumazentrum Ruhrgebiet, Herne, Germany

Background: A classification of axial spondyloarthritis (axSpA) by the imaging arm of the ASAS criteria relies partly on the detection of a bone marrow oedema (BME) in the magnetic resonance imaging (MRI) of the sacroiliac joints (SIJ) suspicious of $\mathrm{SpA}$.

Objectives: To evaluate different types of MRI changes possibly relevant for a diagnosis of axSpA as judged by radiologists taking the rheumatologist's diagnosis as gold-standard.

Methods: Consecutive patients $<45$ years were included if they presented in a specialised rheumatologic centre with chronic low back pain (duration $>3$ months). Patients underwent a complete diagnostic workup including MRI of the SIJ. All clinical and laboratory information including images but no radiological reports was available for experienced rheumatologists to make a diagnosis of axSpA or non-axSpA. In parallel, two experienced musculoskeletal radiologists, blinded to patients' demographics and symptoms (except for back pain) evaluated all MR images without knowledge of the rheumatologist's diagnosis, by quantification of BME, fat metaplasia, erosions, sclerosis and ankylosis based on the Berlin SIJ score. The radiologists also stated whether the patient is likely to have axSpA or not, solely based on MRI findings.

Results: A total of 100 patients were recruited. The rheumatologist diagnosed axSpA in 54 patients (mean age $31.5 \pm 8.0$ years, $77.8 \%$ HLA-B27+, mean symptom duration $36.4 \pm 42.0$ months), while 46 patients were diagnosed as non-specific back pain (age $33.6 \pm 7.1$ years, 17.4\% HLA-B27+, mean symptom duration $25.5 \pm 31.6$ months). According to the radiologists, 38 patients were identified as axSpA, 34 of which were also diagnosed as axSpA by the rheumatologist (overall agreement with the clinical diagnosis: $63 \%$ ), and 4 patients were thought to have axSpA by the radiologist but not by the rheumatologist (disagreement with the clinical diagnosis: $8.7 \%$ ). Similarly, the quantification of MRIs showed higher scores in patients diagnosed as axSpA by the rheumatologist (Tab.1). Only few patients had sclerosis or ankylosis.

From the radiologist's perspective, the calculated odds ratio $(\mathrm{OR})$ for identification of axSpA by MRI only was $3.1(95 \% \mathrm{Cl}: 1.4-7.1)$ for the presence of $\mathrm{BME}, 3.5$ (95\% Cl:1.4-9.0) for fat metaplasia, 2.8 (95\% Cl:1.1-7.0) for erosions, $2.0(95 \%$ $\mathrm{Cl}: 0.7-5.5)$. For the combination of BME and any structural change, the OR was 3.7 (95\% Cl:1.6-8.5)

Tab. 1: Mean/median scores \pm standard deviation for inflammatory and chronic lesions based on the Berlin SIJ score

\begin{tabular}{lcccc}
\hline & Lesion type & axSpA & $\begin{array}{c}\text { non- } \\
\text { SpA }\end{array}$ & p-value \\
\hline Mean & Total score & 12.3 & $4.4 \pm 4.8$ & $\mathrm{p}<0.001$ \\
\pm SD & & \pm 11.8 & & \\
& BME & $3.3 \pm 3.8$ & $1.1 \pm 1.5$ & $\mathrm{p}=0.001$ \\
& Fat metaplasia & $3.4 \pm 5.4$ & $1.0 \pm 3.0$ & $\mathrm{p}=0.004$ \\
& Erosions & $3.2 \pm 5.8$ & $0.7 \pm 2.1$ & $\mathrm{p}=0.011$ \\
\multirow{3}{*}{ Median } & Sclerosis or & 0 & 0 & \\
& Ankylosis & & & \\
& & & &
\end{tabular}

Conclusions: This study reveals a discrepancy between the rheumatologist's and the radiologist's identification of axSpA, confirming that a diagnosis of axSpA in daily practice should not rely on imaging findings only. Nevertheless, the overall specificity of the radiologists was acceptable, although the sensitivity was relatively low. These data suggest also that not only BME but also fat metaplasia and erosions are of value to diagnose axSpA, beyond classification. The combination of MRI changes seems to enhance the discriminative diagnostic performance.

REFERENCE

[1] Lambert R, et al. Ann Rheum Dis 1016.

Disclosure of Interest: None declared

DOI: 10.1136/annrheumdis-2018-eular.7544 
FRIDAY, 15 JUNE 2018

\section{Crystal diseases, metabolic bone diseases and bone diseases other than osteoporosis}

\section{FRI0220 ULTRASOUND IN ASSESSMENT OF DISEASE COURSE IN GOUT: THE 24 MONTH SINGLE-CENTRE PROSPECTIVE OBSERVATIONAL STUDY}

E. Norkuviene ${ }^{1}$, M. Petraitis ${ }^{1}$, I. Apanaviciene ${ }^{1}$, S. Ottaviani ${ }^{2}$, A. Baranauskaite ${ }^{1}$. ${ }^{1}$ Rheumatology, Lithuanian University of Health Sciences, Kaunas, Lithuania; ${ }^{2}$ Rheumatology, Hopital Bichat, APHP, Paris, France

Background: Today, despite the great potential of ultrasound (US) in gout, there is lack of longer duration US follow - up studies in this disease.

Objectives: The aim was to evaluate the 24 month's treatment effect of uratelowering therapy on gout-specific US lesions and to determine the most representative target for US follow-up in gout.

Methods: A 24 month prospective observational single-centre study was carried out. Patients with gout diagnosis, confirmed by identification of monosodium urate crystals, with at least one tophus in the joint or tendon or one double contour sign (DC) on US, were selected for the study. The serum uric acid (SUA) level was assessed every three months. US evaluations of 36 joints and four tendons ( $\mathrm{m}$. triceps and patellar) were performed every six months starting from the baseline, by one rheumatologist, blinded to the SUA levels and clinical data. Outcomes were: change in US features (tophus, DC count and tophus size) in joints and tendons according median of SUA level during the follow up period from M3 to M24. Two stages of SUA levels were defined: high, $\geq 360 \mu \mathrm{mol} / /$; and low, $<360 \mu \mathrm{mol} / \mathrm{l}$ (considered as within the treatment target). Correlations between US findings modifications in different locations, and between US findings modifications and SUA levels, were estimated by the Pearson correlation coefficient.

Results: We included 40 gouty patients (mean \pm SD age $54.1 \pm 9.7$ years, $90.0 \%$ males, disease duration $8.5 \pm 8.8$ years). Mean \pm SD baseline SUA level was 504.8 $\pm 32.9 \mu \mathrm{mol} / \mathrm{l}$

Among the 31 completers at M24, 21 (71\%) achieved median SUA $<360 \mu \mathrm{mol} / \mathrm{l}$ On month 24 the global number of patients with DC and tophus was reduced from $91 \%$ to $32 \%$ and from $100 \%$ to $64 \%$, respectively. A total of sixty-four percent of patients in the study had not reached the US cure (DC or T being still found in at least one joint or tendon) after two years of treatment in the group with the median of SUA less than $360 \mu \mathrm{mol} / \mathrm{l}$. The comparison of crystal clearing process in joints and tendons showed an excellent correlation of mean percentage change in total tophus number ( $\mathrm{rs}=0.900$ ) and size ( $\mathrm{rs}=1.0$ ) in joints and tendons, investigating 21 gout patients who participated in all five US study visits during the 24 months of follow-up. A strong positive correlation was observed between the changes of tophus size in left and right first MTP joints ( $r=0.718$ [95\% confidence interval: $0.370 ; 0.875], p<0.001)$ also between the changes of tophus size in toe and total intra-articular tophus size, measured by US $(\mathrm{r}=0.726$ [95\% confidence interval: $0.347 ; 0.925$ ], $p<0.001$ ) on month 24 (compared to month 0 ). It was found a negative correlation between the mean SUA during 24 months follow up and the reduction in tophus size on month $24(\mathrm{r}=0.602)$
Conclusions: Only one third of patients with median SUA $<360 \mu \mathrm{mol} / /$ were free of US gout signs after 2 years of treatment. Due to positive link between the change in tophus size in the first MTP joint and changes in the whole intraarticular urate pool, also tendons, the tophaceous deposition in the first MTP joint could be the most representative target for follow-up morphological analysis in gout clinical trials or monitoring the disease's activity in clinical practice with US.

Disclosure of Interest: None declared

DOI: 10.1136/annrheumdis-2018-eular.7562

\section{FRI0221 GOUT IS ASSOCIATED WITH AN INCREASED RISK OF CANCER - A NATIONWIDE COHORT STUDY INCLUDING OVER 70,000 GOUT PATIENTS}

K. Zobbe ${ }^{1,2}$, D. Prieto-Alhambra ${ }^{3,4}$, R. Cordtz ${ }^{1,2}$, L. Mellemkjær ${ }^{5}$, P. Højgaard ${ }^{1,2}$, L. E. Kristensen ${ }^{1}$, L. Dreyer ${ }^{1,2,6} .{ }^{1}$ The Parker Institute, Bispebjerg and Frederiksberg Hospital, Frederiksberg; ${ }^{2}$ Center for Rheumatology and Spine Diseases, Rigshospitalet/Glostrup, Hellerup, Denmark, ${ }^{3}$ GREMPAL Research Group, Idiap Jordi Gol and CIBERFes, Universitat Autònoma de Barcelona and Instituto de Salud Carlos III, Barcelona, Spain; ${ }^{4}$ Centre for Statistics in Medicine, NDORMS, University of Oxford, Oxford, UK; ${ }^{5}$ Danish Cancer Society Research Center, Copenhagen; ${ }^{6}$ Department of Rheumatology, Aalborg University Hospital, Aalborg, Denmark

Background: In addition to the possible carcinogenic effect of chronic inflammation, gout patients may experience increased risk of cancer due to additional risk factors such as obesity, diabetes, sedentary lifestyle, smoking and increased alcohol consumption. There is limited data on the association between gout and different cancer types. We investigated the incidence of cancer among Danish gout patients compared to national cancer rates.

Methods: All patients diagnosed with gout in the period 1978-2015 according to the Danish National Patient Registry (including in- and outpatient hospital contacts) were linked with The Danish Cancer Registry to identify incident cancers. Follow-up for cancer started at date of first gout diagnosis and ended at date of cancer, death, emigration or end of 2015, whichever came first. Standardised incidence ratios (SIR) were calculated using sex and 5 year age and calendar-specific incidence rates for first primary cancers in the general population in Denmark. Results: We observed 6205 first primary cancers among 70591 gout patients Compared to an expected number of 5308 in the general population, this corresponded to a SIR for any-cancer of 1.17 (95\% confidence interval (Cl): 1.141.20). SIRs were highest for cancer sites associated with smoking, obesity and excess alcohol consumption: mouth/tongue, pharynx, oesophagus, liver, pancreas, lung, pleura and kidney (table 1). Excess risks were also observed for colorectal cancer, breast cancer, endometrial cancer, multiple myeloma and other types of leukaemia but not for Hodgkin and Non-Hodgkin lymphomas.

Conclusions: Gout patients are at risk of cancer, especially cancer types associated with smoking, obesity and excess alcohol consumption, but also multiple myeloma and leukaemia. It is unknown if uric-acid lowering therapy and/or lifestyle changes reduce this risk.

\begin{tabular}{|c|c|c|c|c|c|c|c|c|}
\hline Cancer site & Obs & SIR $(95 \% \mathrm{Cl})$ & Cancer site & Obs & SIR $(95 \% \mathrm{Cl})$ & Cancer site & Obs & $\underline{\operatorname{SIR}(95 \% \mathrm{CI})}$ \\
\hline \multicolumn{3}{|c|}{ Buccal cavity and pharynx } & \multicolumn{3}{|c|}{ Respiratory system } & \multicolumn{3}{|c|}{ Male genital organs } \\
\hline Lip & 14 & $\begin{array}{c}0.74(0.40- \\
1.24)\end{array}$ & $\begin{array}{l}\text { Nasal, ear, } \\
\text { sinus }\end{array}$ & 11 & $\begin{array}{c}0.89(0.44- \\
1.59)\end{array}$ & Prostate & 973 & $\begin{array}{c}1.01(0.95- \\
1.08)\end{array}$ \\
\hline $\begin{array}{l}\text { Tongue/ } \\
\text { mouth }\end{array}$ & 88 & $\begin{array}{c}1.57(1.27- \\
1.93)\end{array}$ & Larynx & 66 & $\begin{array}{c}1.18(0.91- \\
1.50)\end{array}$ & Testis & 28 & $\begin{array}{c}1.40(0.93- \\
2.02)\end{array}$ \\
\hline Pharynx & 99 & $\begin{array}{c}1.93(1.57- \\
2.35)\end{array}$ & Lung & 863 & $\begin{array}{c}1.12(1.05- \\
1.20)\end{array}$ & \multicolumn{3}{|c|}{ Urinary tract } \\
\hline Digestive organs & & & Pleura & 11 & $\begin{array}{c}5.53(2.76- \\
9.89)\end{array}$ & Kidney & 214 & $\begin{array}{c}1.80(1.57- \\
2.06)\end{array}$ \\
\hline Oesophagus & 116 & $\begin{array}{c}1.32(1.09- \\
1.59)\end{array}$ & Melanoma & 184 & $\begin{array}{c}0.99(0.85- \\
1.15)\end{array}$ & $\begin{array}{c}\text { Renal pelvis and } \\
\text { ureter }\end{array}$ & 34 & $\begin{array}{c}1.16(0.80- \\
1.62)\end{array}$ \\
\hline Stomach & 149 & $\begin{array}{c}1.04(0.88- \\
1.22)\end{array}$ & Breast & 385 & $\begin{array}{c}1.17(1.06- \\
1.29)\end{array}$ & Urinary bladder & 462 & $\begin{array}{c}1.07(0.98- \\
1.18)\end{array}$ \\
\hline $\begin{array}{c}\text { Small } \\
\text { intestine }\end{array}$ & 20 & $\begin{array}{c}1.28(0.78- \\
1.98)\end{array}$ & \multicolumn{3}{|c|}{ Female genital organs } & \multicolumn{3}{|c|}{ Lymphatic and hematopoietic tissues } \\
\hline Colon & 636 & $\begin{array}{c}1.18(1.09- \\
1.28)\end{array}$ & External & 15 & $\begin{array}{c}1.07(0.60- \\
1.76)\end{array}$ & Hodgkin & 10 & $\begin{array}{c}0.84(0.40- \\
1.55)\end{array}$ \\
\hline Rectum & 326 & $\begin{array}{c}1.11(1.00- \\
1.24)\end{array}$ & Cervix & 29 & $\begin{array}{c}1.21(0.81- \\
1.74)\end{array}$ & Non-Hodgkin & 124 & $\begin{array}{c}0.77(0.64- \\
0.92)\end{array}$ \\
\hline Liver & 158 & $\begin{array}{l}2.24(1.90- \\
2.62)\end{array}$ & Endometrial & 114 & $\begin{array}{c}1.75(1.44- \\
2.10)\end{array}$ & Multiple myeloma & 98 & $\begin{array}{c}1.37(1.11- \\
1.67)\end{array}$ \\
\hline Gallbladder & 50 & $\begin{array}{c}1.26(0.93- \\
1.66)\end{array}$ & Ovary & 39 & $\begin{array}{c}0.79(0.56- \\
1.08)\end{array}$ & Lymphatic leukaemia & 97 & $\begin{array}{c}1.09(0.88- \\
1.33)\end{array}$ \\
\hline Pancreas & 238 & $\begin{array}{c}1.41(1.23- \\
1.60)\end{array}$ & & & & Other leukaemia & 101 & $\begin{array}{c}1.59(1.31- \\
1.94)\end{array}$ \\
\hline
\end{tabular}

